\title{
Financial Industry Dynamics
}

\author{
Tim Landvoigt \\ University of Texas-Austin
}

\author{
Richard Lowery \\ University of Texas-Austin
}

January 2015

\begin{abstract}
To explain the sources of heterogeneity and fragility in the financial sector, we develop a dynamic model of entry, exit, and firm quality in the market for issuance and trading of complex financial securities. Firm quality has two dimensions; security production expertise, which creates a positive externality for other firms, and trading expertise, which allows firms to obtain more favorable prices when trading with other firms. We find that increasing the quality of securities, which in the model increases the scope for investment in trading expertise, leads to markets that exhibit greater concentration, firm heterogeneity, fragility, and price dispersion.
\end{abstract}




\section{Introduction}

The financial sector exhibit a significant degree of heterogeneity among firms, consistent with the general observation of Pakes and McGuire (1994) about real economy firms. For example, the "big five" investment banking firms operated alongside small, boutique investment banking firms. Large, highly regarded securities underwriters compete with small issuers when issuing and trading securitized products. At the same time, trades in such products are highly concentrated among a few dominant players, as is apparent from Figure 1, with greater security complexity seemingly related to greater concentration. A small literature is developing in finance to try to understand these feature of the financial sector. For example Chaderina and Green (2014) ask why relatively unsophisticated firms would choose to remain in the securities trading market, leaving themselves as "prey" for more sophisticated players. We contribute to this field by developing a model of industry dynamics with a microfounded model of the financial sector embedded in an extension of a standard oligopoly model from industrial organization.

Our model is designed to capture the fundamental characteristics of trading in over-thecounter style markets. We can then investigate the relationship between the characteristics of the financial production function and the characteristics of this industry. These characteristics include the following observations. First, markets for security issuance and derivatives trading in over-the-counter markets are often dominated by a relatively small set of firms, as discussed, for example, in Atkeson, Eisfeldt, and Weill (2013). This situation occurs despite relatively large profit margins and the absence of the canonical barriers to entry such as patent protections or large technological fixed costs. Second, the primary and secondary markets for many types of financial securities exhibit large fluctuations in participation and volume; this is particularly true for securities with greater complexity. Finally, prices in these markets are dispersed, with the same or very similar securities trading at different

prices at almost the exact same time (Green, Hollifield, and Schürhoff, 2007). Heterogeneity in prices most likely reflects heterogeneity in bargaining power or expertise, with dominant firms earning greater profits on average. 


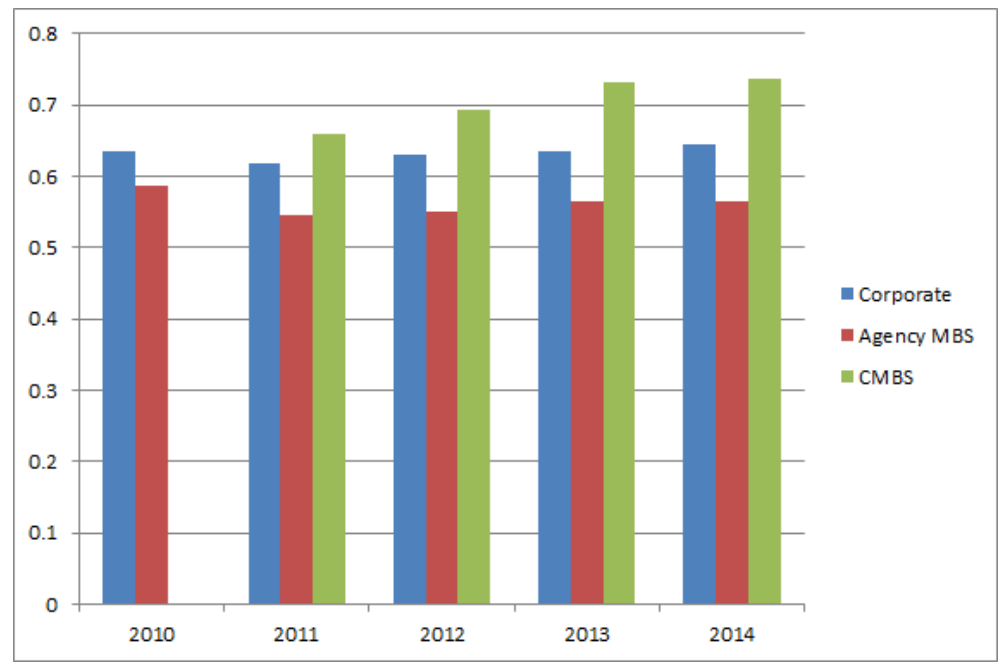

Figure 1: Share of trades reported to TRACE by top 10 firms in the market for corporate debt, agency mortgage backed securities, and commercial mortgage backed securities.

Our starting point is a dynamic model of entry, exit, and investment, in the spirit of Ericson and Pakes (1995). Our focus is on new issuance of financial securities such as, for example, corporate bonds or asset backed securities, along with their subsequent trading in OTC markets. Since the model is dynamic, firms may enter or remain in the market in anticipation of the future market structure, even if the current state of the market is unfavorable to them. In the model, financial firms engage in security production and security trading. Firms also choose to invest resources in improving both their ability to create better securities and in their ability to value, and therefore profitably trade, existing securities, as in the static model of Glode and Lowery (2015).

The two types of expertise that firms in our financial sector develop have different effects on industry structure and competition. When firms invest in the first kind of expertise, they are able to produce better securities, and other firms may benefit if the producing firm sells the security to them. Thus, one dimension of quality investment generates a positive externality on "competing" firms. On the other hand, investment in valuing assets serves to improve the investor's terms of trade with a competitor, thus producing an advantage in a zero-sum sense. The second dimension of quality therefore imposes a negative externality on other firms. As in Glode and Lowery (2015), valuation expertise allows firms to learn about 
the dimensions of security value generated through investment in security design expertise. Roughly speaking, low quality securities simply pay off in accordance with general economic conditions, and their is no scope for learning more about these conditions than what is publicly available. These characteristics of the financial market we model lead to more subtle effects of entry and exit of competitors when compared to a typical model of product market competition. A new entrant into the security production and trading industry represents more competition for trades, but also a new source of potential trades. Further, our financial sector can suffer from adverse selection problems if the firms differ sufficiently in their trading expertise levels, or if there is excessive investment in trading expertise given the level of security production expertise.

To analyze the model, we compute statistics describing the moments of industry characteristics under different parameter assumptions. In the main analysis, we vary the parameters along two different dimensions. We compare industries where trading expertise is relatively cheap to acquire to industries where trading expertise is prohibitively expensive, and we compare industries where the baseline security quality is high to industries with low baseline security quality. We carry out the analysis on a $2 \times 2$ parameter grid, such that we evaluate the industry under four possible configurations.

We find in numerical simulations of our model economies that the expertise structure of an industry is the key determinant of entry and exit decisions. While it is generally more attractive to participate in an industry with a high average level of security design expertise, the opposite is true for trading expertise. A potential entrant who starts out with little expertise and is facing many highly informed incumbents as potential trading partners anticipates that adverse selection will cause lower trading profits due to the large difference in information. This may effectively deter entry. At the same time, the incumbents have strong incentives to maintain their already high level of trading expertise so they do not fall behind their competitors. Hence investment in trading expertise solidifies small industries with high levels of zero-sum investment activity. This prediction of our model addresses the stylized fact that financial industries can simultaneously exhibit high concentration and 
profit margins: the information structure is the barrier to entry.

Our numerical simulations further show that industries with higher baseline security quality, and thus greater scope for investment in trading expertise, also feature greater fragility. Such industries can quickly evolve from a state with many participants of relatively low and homogeneous trading expertise to a state with few active firms, all with high levels of trading expertise. The industries with many homogeneous firms produce more securities and spend fewer resources on developing trading expertise as firms are not concerned about being "outsmarted" by their trading partners. If, however, one or two firms succeed in developing greater trading expertise, then participation in the industry becomes less attractive for their less informed competitors. When several of the less informed firms exit, this creates even greater incentives for the remaining firms to ramp up their investment in trading expertise, leading to feedback loop that causes a fast transition to the new industry structure. Hence the simulated time series of our industries exhibit sudden exit waves and breakdowns in activity. This model prediction speaks to the stylized observation on the fragility and volatility of financial markets for complex securities. Our analysis further shows that industries with greater heterogeneity in expertise also imply greater heterogeneity in observed prices. Since heterogeneity in expertise is endogenously determined, price dispersion effectively becomes a function of the complexity of the underlying security as well, which matches with empirical facts on trading in OTC markets.

The different industry structures that arise for different parameter regions have important implications for the overall profitability of the financial sector. In particular, when trading expertise is effective, the exogenous increase in security quality lowers, rather than increases, the total value in the financial sector. This result arises even though the lowest quality security in the high quality treatment is weakly better than the best security is the low quality treatment. Unsurprisingly, then, the average quality of the security is higher in the high quality treatment. Raising the security quality, however, raises the incentives for firms to invest in trading expertise. Much of the value from the higher quality securities is then lost through socially wasteful spending on trading expertise. This effect cannot fully 
account for the lower total surplus created in the high quality security case. When securities are better, and thus trading expertise more valuable, firms will invest in additional trading expertise in order to expropriate the additional surplus. Firms, however, would not expend more additional resources expropriating the additional surplus than the total amount of additional surplus available. A second effect, operating on the extensive margin, arises that leads to an overall decrease in surplus.

The source of this second effect is the negative externality that entrants can impose on the market via adverse selection. When security quality is high, potential entrants may be tempted to enter the market even when the trading expertise of the incumbents is high. New entrants start with a low level of expertise, but since they are aware of their own informational disadvantage they can trade carefully and still capture some benefits from the high quality security. Further, through investment they may be able to raise their information quality in the future. The presence of these new entrants then leads to an increase in the frequency of trade breakdowns as the new, low quality entrants crowd out some of the efficient trade between sophisticated incumbents. Entrants do not fully internalize these adverse selection costs, thus leading to entry that may be excessive from a social welfare perspective.

While our current model predictions are stylized and qualitative, the model has the potential for a serious quantitative application to different types of financial markets. More generally, the modeling approach we take in this paper will be a fruitful way to characterize other types of strategic interactions in the financial industry. In this paper we focus on trading interactions where information acquisition only serves the purpose of improving the split of the surplus in favor of each individual trader. However, we can also apply our methodology to other settings, in which information acquisition has positive externalities for the industry, as would be the case for traders who interact on an exchange platform that allows all parties to learn from publicly observed prices.

Related Literature This paper relates to several strands of literature. First, it contributes to the recent literature on financial market structure and trading outcomes. Starting with 
Duffie, Grleanu, and Pedersen (2005), many recent papers employ search frictions to analyze trade in OTC markets. Most closely related to our paper Golosov, Lorenzoni, and Tsyvinski (2014), and Babus and Kondor (2013) also study the effects of information externalities, and Guerrieri and Shimer (2012) and Chang (2014) study adverse selection in financial markets using a search framework. Glode, Green, and Lowery (2012) study a two period model where endogenously acquired expertise can lead to trade breakdown, and Bolton, Santos, and Scheinkman (2015) study a three period model with a productive sector and a trading sector. Daley and Green (2012) studies a dynamic model of adverse selection, but without entry and exit decisions. Several other recent papers study the effect that linkages between intermediaries and the shape of the intermediation network have on systemic risk, including Eisenberg and Noe (2001), Babus and Hu (2015), and Farboodi (2015). While we abstract away from search frictions and balance sheet linkages, we also study a model of bilateral trading interactions and in addition explicitly consider dynamic entry, exit, and expertise investment decisions. Afonso (2011) studies externalities of entry decision for incumbent investors.

The two papers most closely related to ours are Chaderina and Green (2014) and Atkeson, Eisfeldt, and Weill (2015). Both papers consider entry and exit in financial markets with heterogenous firms. Our paper is distinct, however, in focusing on the endogenous acquisition of two dimensional expertise. Chaderina and Green (2014) focus instead on the process through which firms learn about their exogenously given ability. Just this learning process alone generates the interesting dynamics in that model, where exit decisions by low ability traders exacerbate exogenous economic shocks. Still, their model and ours both capture similar ideas about the potential for skill cycles in finance. Atkeson, Eisfeldt, and Weill (2015), on the other hand, study a model where firm heterogeneity is also exogenous but is only in terms of the initial endowment and size, rather than skill. This heterogeneity generates differential bargaining power, leading to nontrivial equilibrium entry and exit decisions.

Our paper also relates to the literature on computable industry dynamics in industrial organization following the seminal work of Ericson and Pakes (1995). We follow the general 
structure in Doraszelski and Satterthwaite (2010) and the continuous time approach developed in Doraszelski and Judd (2012). We contribute by considering investment in two types of skill, one of which imposes a positive and one a negative externality on other players.

\section{Model}

\subsection{Entry, exit, and expertise investment}

Setup Time is continuous, with $t \in(0, \infty)$. There are $N$ firms, and at any instant $N_{A}$ are active and $N_{I}$ are inactive. Each active firm $i$ exists in an expertise state $\omega^{i}=\left\{\omega_{m}^{i}, \omega_{e}^{i}\right\}$, with $\omega_{k}^{i} \in\left\{k_{1}, \ldots, k_{M_{k}}\right\}$ for $k \in\{m, e\}$, and where there are $M_{k}$ expertise levels for skill type $k$. Here, $m$ represents security production expertise, also referred to as surplus creation expertise, and $e$ represents trading expertise. Hence each active firm can exist in $M=$ $M_{m} \times M_{e}$ total different states. All inactive firms exist in state $\omega^{i}=M+1$, which simply indicates their status as being inactive.

Security production and trading opportunities arrive for active firms according to a Poisson process with intensity $\lambda\left(N_{A}\right)$, i.e., the arrival intensity depends on the total number of active firms. Conditional on a opportunity arising, two firms participate, with every active firm having an equal probability of participation. When the production/trading opportunity arrives, each selected firm produces a security. Then, one of the two firms is hit with a liquidity shock and must sell the security in question or lose its entire value. Securities produced and acquired by the firm that does not face the liquidity shock then pay off. For simplicity, we assume that all these steps occur sequentially but within the same instant; nothing of importance would change if the process more realistically took a positive amount of time.

We denote the vector of all individual states by $\boldsymbol{\omega}=\left(\omega^{i}\right)_{i=1}^{N_{A}+N_{I}}$; this is the aggregate state of the economy. Further, denote the set of all active and inactive firms by $\mathcal{N}_{A}$ and $\mathcal{N}_{I}$, respectively. Defining the value to agent $i$ for trading with agent $j$ as $\pi_{i}\left(\omega^{i}, \omega^{j}, \boldsymbol{\omega}\right)$, the 
expected flow payoff to agent $i$ (per unit of time) is

$$
\tilde{\pi}_{i}(\boldsymbol{\omega})=\lambda\left(N_{A}\right) \frac{2}{N_{A}} \sum_{j \in \mathcal{N}_{A}, j \neq i} \pi_{i}\left(\omega^{i}, \omega^{j}, \boldsymbol{\omega}\right) .
$$

The expected number of trading events over one period is given by $\lambda\left(N_{A}\right)$, and for each event two firms are selected.

We model entry and exit opportunities as arriving following a Poisson process, with the arrival intensities depending on each firm's actions. Inactive firm have a costly choice that determines their the entry hazard, and incumbents choose their exit hazard. Specifically, entry or exit for firm $i$ occurs at rate $h^{z}\left(x^{i, z}\right)$, where firm $i$ selects $x^{i, z}$ continuously. Upon exit, the incumbent firm collects a scrap value $\Phi_{e x}\left(x^{i, z}\right)$, where $\Phi_{e x}()$ is an increasing function of the exit intensity $x^{i, z}$. Analogously, upon entry the previously inactive firm pays setup $\operatorname{cost} \Phi_{e n}\left(x^{i, z}\right)$, with $\Phi_{e n}()$ being a decreasing function of entry hazard $x^{i, z}$. This approach implies that there is zero probability than any two firms will simultaneously enter or exit. Further, the continuous entry and exit actions guarantee the existence of a pure strategy equilibrium in entry and exit (see Doraszelski and Satterthwaite (2010)). All active firms continuously invest along the two dimensions of expertise, choosing investment policies $x^{i, k}$, $k \in\{m, e\}$. Investing along a dimension increases the likelihood of moving up to the next quality ladder rung in that dimension, with a hazard rate of $h^{k}\left(x^{i, k}\right)$. There is also a random depreciation shock for each level of expertise, arriving with Poisson intensity $\delta_{k}$; when a firm is hit by such a shock it drops one level on the quality ladder. The initial state of an entering firm is $\underline{\omega}=\left\{\underline{\omega}_{m}, \underline{\omega}_{e}\right\}$. In our benchmark model, we will assume that firms enter on the lowest rung for each expertise dimension. Our model thus captures the idea that newer firms must work their way up within the financial industry, as in Ljungqvist, Marston, and Wilhelm (2009). All firms have a common discount rate $\rho$. We further allow for an exogenous aggregate industry state $\xi \in\{1, \ldots, \Xi\}$ that scales the payoffs of all firms and follows a continuous-time Markov chain. 
Incumbent Problem The instantaneous value to an active firm $i$ is given by:

$$
\begin{aligned}
& \rho V_{I}^{i}(\boldsymbol{\omega} ; \xi)=\max _{\left\{x^{i, k}\right\}_{k=m, e, z} \in \mathbb{X}_{I}^{k}(\omega)} \tilde{\pi}_{i}(\boldsymbol{\omega}, \xi)-\sum_{k=m, e, z} x^{i, k} \\
& +\sum_{k=m, e} h^{k}\left(x^{i, k} 1_{\left\{\omega_{k}^{i}+1 \neq M_{k}\right\}}\left[V_{I}^{i}\left(\omega_{k}^{i}+1, \boldsymbol{\omega}^{-i} ; \xi\right)-V_{I}^{i}(\boldsymbol{\omega}, \xi)\right]\right. \\
& +\sum_{\left\{j \neq i, \omega^{j} \neq M+1\right\}} \sum_{k=m, e} h^{k}\left(X_{I}^{j, k}(\boldsymbol{\omega} ; \xi)\right) 1_{\left\{\omega_{k}^{j}+1 \neq M_{k}\right\}}\left[V_{I}^{i}\left(\omega_{k}^{j}+1, \boldsymbol{\omega}^{-j} ; \xi\right)-V_{I}^{i}(\omega ; \xi)\right] \\
& +\sum_{\left\{j: \omega^{j} \neq M+1\right\}} \delta 1_{\left\{\omega_{k}^{j} \neq 1\right\}}\left[V_{I}^{i}\left(\omega_{k}^{j}-1, \boldsymbol{\omega}^{-j} ; \xi\right)-V_{I}^{i}(\boldsymbol{\omega} ; \xi)\right] \\
& +h^{z}\left(x^{i, z}\right)\left[\Phi_{e x}\left(x^{i, z}\right)+V_{E}^{i}\left(\omega^{i}=M+1, \boldsymbol{\omega}^{-i} ; \xi\right)-V_{I}^{i}(\boldsymbol{\omega} ; \xi)\right] \\
& +\sum_{\left\{j \neq i: \omega^{j} \neq M+1\right\}} h^{z}\left(X_{I}^{j, z}(\boldsymbol{\omega} ; \xi)\right)\left[V_{I}^{i}\left(\omega^{j}=M+1, \boldsymbol{\omega}^{-j} ; \xi\right)-V_{I}^{i}(\boldsymbol{\omega} ; \xi)\right] \\
& +\sum_{\left\{j: \omega^{j}=M+1\right\}} h^{z}\left(X_{E}^{j, z}(\boldsymbol{\omega}, \xi)\right)\left[V_{I}^{i}\left(\omega^{j}=\underline{\omega}, \boldsymbol{\omega}^{-j} ; \xi\right)-V_{I}^{i}(\boldsymbol{\omega} ; \xi)\right) \\
& +h^{\xi}\left(\xi, \xi^{+}\right)\left[V_{I}^{i}\left(\boldsymbol{\omega}, \xi^{+}\right)-V_{I}^{i}(\boldsymbol{\omega}, \xi)\right] .
\end{aligned}
$$

Here, the first line of equation (2) gives the flow payoff as defined above in (1) and investment costs. Line 2 are quality ladder improvement events for agent $i$. The third line gives the contribution to the value from other agent's investment successes, while the fourth line gives the contribution from depreciation events for all agents, including agent $i$. The fifth and sixth lines add exit, the seventh line entry, and the eighth line changes to the exogenous state, with $h^{\xi}$ being the conditional transition hazard for $\xi$. 
Entrant Problem For a potential entrant, the value is given by:

$$
\begin{aligned}
\rho V_{E}^{i}(\boldsymbol{\omega} ; \xi)= & \max _{x^{i, z} \in \mathbb{X}_{E}^{i}(\omega)}-x^{i, z} \\
& +\sum_{\left\{j \neq i, \omega^{j} \neq M+1\right\}} \sum_{k=m, e} h^{k}\left(X_{I}^{j, k}(\boldsymbol{\omega} ; \xi)\right) 1_{\left\{\omega_{k}^{j}+1 \neq M_{k}\right\}}\left[V_{E}^{i}\left(\omega_{k}^{j}+1, \boldsymbol{\omega}^{-j} ; \xi\right)-V_{E}^{i}(\omega ; \xi)\right] \\
& +\sum_{\left\{j: \omega^{j} \neq M+1\right\}} \delta 1_{\left\{\omega_{k}^{j} \neq 1\right\}}\left[V_{E}^{i}\left(\omega_{k}^{j}-1, \boldsymbol{\omega}^{-j} ; \xi\right)-V_{E}^{i}(\boldsymbol{\omega} ; \xi)\right] \\
& +\sum_{\left\{j \neq i: \omega^{j} \neq M+1\right\}} h^{z}\left(X_{I}^{j, z}(\boldsymbol{\omega} ; \xi)\right)\left[V_{E}^{i}\left(\omega^{j}=M+1, \boldsymbol{\omega}^{-j} ; \xi\right)-V_{E}^{i}(\boldsymbol{\omega} ; \xi)\right] \\
& +h^{z}\left(x^{i, z}\right)\left[-\Phi_{e n}\left(x^{i, z}\right)+V_{I}^{i}\left(\omega^{i}=\underline{\omega}, \boldsymbol{\omega}^{-i} ; \xi\right)-V_{E}^{i}(\boldsymbol{\omega} ; \xi)\right] \\
& +\sum_{\left\{j: j \neq i, \omega^{j}=M+1\right\}} h^{z}\left(X_{E}^{j, z}(\boldsymbol{\omega}, \xi)\right)\left[V_{E}^{i}\left(\omega^{j}=\underline{\omega}, \boldsymbol{\omega}^{-j} ; \xi\right)-V_{E}^{i}(\boldsymbol{\omega} ; \xi)\right) \\
& +h^{\xi}\left(\xi, \xi^{+}\right)\left[V_{E}^{i}\left(\boldsymbol{\omega}, \xi^{+}\right)-V_{E}^{i}(\boldsymbol{\omega}, \xi)\right] .
\end{aligned}
$$

The first line of equation (3) is the cost of the entry hazard, which is the entrant's only choice variable. The second to fourth lines reflect the change in the entrant's value if active incumbent firms move up or down the expertise ladder in either dimension or exit. The fifth line adds the own entry, and the sixth line the entry hazard of all other inactive firms. Line seven is the change in the aggregate industry state.

\subsection{Trading Game}

Setup This section describes the strategic interaction of the two selected firms upon arrival of trading opportunity, defining the payoff function in equation (1). First, the two selected firms each have an opportunity to develop a security. The security can either be a good security or a normal security. Normal securities pay off $\frac{1}{2}$ in expectation. Good securities

pay off based on a hidden state $Z$. When $Z=1$, the good security pays off $\frac{1}{2}(\phi+1), \phi>1$, while if $Z=0$ the good security pays off zero. Since $\phi>1$, the expected value of a good security exceeds the expected value of a normal security. Each firm receives a conditionally 
independent signal $\zeta_{i}$ about $Z$, and the precision of this signal depend on firm $i$ 's trading expertise level ${ }^{1}$ :

$$
\mu_{i} \equiv P\left(\zeta_{i}=Z\right)=\frac{1}{2}+\omega_{e}^{i}
$$

All firms attempt to produce good securities, but their probability of success depends on their security design expertise. Specifically, they succeed only with probability

$$
Q_{i} \equiv \omega_{m}^{i}
$$

Whether the firm succeeds or fails at creating a good security is not revealed until after the security pays off. Prior to the security payoff, one firm is hit with a liquidity shock and must "consume" immediately, as in Diamond and Dybvig (1983). For simplicity, we normalize the outside value of the security to the liquidity desiring firm to zero. This selling firm bargains with the other firm to exchange his security for cash. One of the two firms is selected at random to make a take it or leave it offer. Prior to making the offer, the selected firm observes his signal $\zeta$, which is informative about $Z$. Both firms' trading and security production expertise are common knowledge. The responding firm also observes his signal prior to accepting or rejecting the offer.

Types of equilibria This trading game clearly has a large multiplicity of perfect Bayesian equilibria. We focus on perfect sequential equilibria, and we restrict attention to those perfect sequential equilibria in which the proposer plays a pure strategy, and, whenever possible, the responder also plays a pure strategy. ${ }^{2}$ Since all information about expertise is common knowledge and we focus on Markov perfect equilibria in the dynamic game, we can analyze the two trading subgames of the static model generated by the selection of the proposer.

\footnotetext{
${ }^{1} \mathrm{~A}$ more structural interpretation of the payoffs for good and normal securities is that the normal security pays off as a function of the market state, while the good security pays off based on the hidden state. In this interpretation, all information about the market state is common knowledge, while information about the hidden state can be discovered through investment in "trading expertise."

${ }^{2}$ Confining attention to such equilibria simplifies the analysis by making the updating problem of the responder as simple as possible. The main characteristics of the stage game equilibrium that are important for industry dynamics are not sensitive to this restriction.
} 
In the case where the "patient" firm (i.e. the firm not hit by a liquidity shock) is selected to make the take-it-or- leave-it offer, the equilibrium outcome is trivial; the patient firm will offer a price of zero to the impatient firm, and the impatient firm will accept. In this case, the patient firm receives the full benefit of any security design expertise on the part of the impatient firm. This is the main channel through which security design expertise (the $m$ dimension of expertise) generates positive externalities. In this case, however, neither firm benefits from trading expertise.

The perhaps more interesting case occurs when the impatient firm is given the opportunity to propose an ask price to the patient firm. In this case we can generally distinguish two types of equilibria, which we will refer to as "pooling" and "separating" equilibrium. In the pooling equilibrium the proposing seller firm will not condition its price offer on its own signal, and the responding buyer firm will always accept the offer, since it knows that the asking price does not reveal information about the proposer's private signal. The transaction price in this equilibrium will be the expected value that the responder assigns to the security (produced by the proposer), conditional on having received a low signal:

$\Pi_{P} \equiv E\left[v_{p} \mid \zeta_{r}=0\right]=P\left(Z=1 \mid \zeta_{r}=0\right)\left[Q_{p} \frac{1}{2}(\phi+1)+\left(1-Q_{p}\right) \frac{1}{2}\right]+P\left(Z=0 \mid \zeta_{r}=0\right)\left(1-Q_{p}\right) \frac{1}{2}$

Here, $r$ indexes the responder, who in this case is the patient firm, while $p$ indexes the proposer, the impatient firm.

In the separating equilibrium the proposer will offer a low asking price if he received a bad signal, and offer a high price if he received a good signal. These offers will be a function of the signal quality of both agents. When the proposer follows a pure strategy, the responder can infer the proposer's information from the offer. Thus, the responder accepts or rejects the offer based, effectively, on his own signal and the signal of the proposer. The proposer can then offer either the price that is the expected value given his own signal when the opponent has the same signal, or the expected value when the opponent has the opposite signal. In the equilibrium on which we focus, the proposer always makes the offer of the 
expected value when the signals conform, so the possible prices are

$$
\begin{aligned}
& \Pi_{S}^{h i} \equiv E\left[v_{p} \mid \zeta_{r}=1, \zeta_{p}=1\right]=P(Z=1 \mid 1,1)\left[Q_{p} \frac{1}{2}(\phi+1)+\left(1-Q_{p}\right) \frac{1}{2}\right]+P(Z=0 \mid 1,1)\left(1-Q_{p}\right) \frac{1}{2} \\
& \Pi_{S}^{l o} \equiv E\left[v_{p} \mid \zeta_{r}=0, \zeta_{p}=0\right]=P(Z=1 \mid 0,0)\left[Q_{p} \frac{1}{2}(\phi+1)+\left(1-Q_{p}\right) \frac{1}{2}\right]+P(Z=0 \mid 0,0)\left(1-Q_{p}\right) \frac{1}{2} .
\end{aligned}
$$

We will generally have $\Pi_{S}^{l o} \leq \Pi_{P} \leq \Pi_{S}^{h i}$, and hence the pooling equilibrium only exists if it is not profitable for the proposer with a high signal to deviate to asking the high price of the separating equilibrium. The separating equilibrium in turn can only exist if a proposer who received a low signal does not want to pretend that he received the high signal. An important feature of the separating equilibrium is that it is subject to ex-post trade breakdown due to adverse selection: if the proposer receives a high signal and asks for the high price that presupposes two high signals, but the responder has actually received a low signal, then trade does not occur. We also treat the case that neither the pooling equilibrium, nor the separating equilibrium in pure strategies exist. In that case, we allow the responder to mix over accepting or rejecting the offer to sustain the separating equilibrium in mixed strategies. Below we will describe the conditions for the existence of the equilibria in greater detail.

Pooling equilibrium When both firms receive sufficiently imprecise signals about the quality of the asset, there is a perfect sequential equilibrium in which the proposing firm ignores his own signal and offers to sell the security to the patient firm at a price equal to the expected value of the patient firm conditional on a bad signal about the state $Z$. The incentive compatibility condition is that the proposer with the good signal prefers to receive $\Pi_{P}$, versus receiving $\Pi_{S h i}$ when only the responder has a good signal. Therefore, the pooling equilibrium exists when

$$
\Pi_{P} \geq P\left(\zeta_{r}=1 \mid \zeta_{p}=1\right) \Pi_{S}^{h i} .
$$


Since $P(Z=1 \mid 1,1)=\frac{\mu_{p} \mu_{r}}{\mu_{p} \mu_{r}+\left(1-\mu_{p}\right)\left(1-\mu_{r}\right)}$, this condition becomes

$$
\begin{aligned}
& \left(1-\mu_{r}\right)\left[Q_{p} \frac{1}{2}(\phi+1)+\left(1-Q_{p}\right) \frac{1}{2}\right]+\mu_{r}\left(1-Q_{p}\right) \frac{1}{2} \geq \\
& \mu_{r} \mu_{p}\left[Q_{p} \frac{1}{2}(\phi+1)+\left(1-Q_{p}\right) \frac{1}{2}\right]+\left(1-\mu_{r}\right)\left(1-\mu_{p}\right)\left(1-Q_{p}\right) \frac{1}{2}
\end{aligned}
$$

After some algebra, this condition becomes

$$
(\phi+1)\left(\frac{\mu_{r} \mu_{p}+\mu_{r}-1}{\mu_{r}+\mu_{p}-2 \mu_{r} \mu_{p}}\right)-\frac{1-Q_{p}}{Q_{p}} \leq 0
$$

When this condition holds, then, the liquidity demanding proposer obtains

$$
E\left[v_{p} \mid \zeta_{r}=0\right]=\frac{1}{2}+\frac{1}{4}(\phi-1) Q_{p}-\frac{1}{2}\left(\mu_{r}-\frac{1}{2}\right)(\phi+1) Q_{p}
$$

while the liquidity supplying responder receives the payoff from his own security, the payoff from the proposer's security, and pays out the expected value of the proposer's security conditional on his own signal being low:

$$
\frac{1}{2}+\frac{1}{4}(\phi-1) Q_{r}+\frac{1}{2}\left(\mu_{r}-\frac{1}{2}\right)(\phi-1) Q_{p}
$$

Here, the responder's own signal decreases the price that the proposer must offer to successfully sell the security following bad news.

Separating equilibrium When this condition is violated, the efficient trading equilibrium cannot be maintained if a deviation to a higher ask price is assumed to come from the type with a high signal; efficient trade cannot take place. In keeping with the analysis in Glode, Green, and Lowery (2012), we consider instead the equilibrium in which a seller with a low signal asks for the lowest reasonable price $\left(\Pi_{S}^{l o}=E\left[v_{p} \mid \zeta_{p}=0, \zeta_{r}=0\right]\right)$ while the seller with the high signal asks for the highest reasonable price $\left(\Pi_{S}^{h i}=E\left[v_{p} \mid \zeta_{p}=1, \zeta_{r}=1\right]\right)$. Focus on this equilibrium can be justified through a number of forward induction arguments. Here, 
trade breaks down when the proposer receives a positive signal while the responder receives a negative signal. In order to maintain incentive compatibility in all cases, the responding firm with the high signal may have to mix over accepting or rejecting the high ask price, and off equilibrium path beliefs must be selected to support such a decision (effectively, surprisingly low price offers must be assumed to come from the low type with a sufficient probability).

The incentive compatibility condition for the low signal, proposing liquidity demander to demand only a low price is

$$
\Pi_{S}^{l o} \geq P\left(\zeta_{r}=1 \mid \zeta_{p}=0\right) \Pi_{S}^{h i}
$$

Since only expectations of value when both signals agree enter this threshold, and since the conditional probability that one signal is the reverse of another is symmetric, for agent $i$ the thresholds for this equilibrium existing are

$$
\begin{aligned}
& \qquad 2 \mu_{i} \mu_{j}+1-\mu_{i}-\mu_{j}+\left(1-\mu_{i}\right)\left(1-\mu_{j}\right)\left(1+Q_{k}(\phi+1)\right) \\
& \left(\mu_{i}\left(1-\mu_{i}\right)+\mu_{j}\left(1-\mu_{i}\right)\right)\left(1 \mu_{i} \mu_{j}+1-\mu_{i}-\mu_{j}+\left(1-\mu_{i}\right)\left(1-\mu_{j}\right)\left(1+Q_{k}(\phi+1)\right)-\left(1-\mu_{i}-\mu_{j}\right)\left(1+Q_{k}(\phi+1)\right)\right) \\
& \text { for } k \in\{i, j\} \text {, where } k \text { indexes the identity of the liquidity demanding proposer (i.e. the } \\
& \text { agent attempting to sell his security). More intuitively, this expression can be written as }
\end{aligned}
$$

Conditional probability of agreement

$$
\begin{aligned}
& \geq \\
& \left(1+Q_{k}(\phi+1)\right) \times \\
& \left(\frac{\text { Conditional probability of disagreement }}{\text { Conditional probability of agreement }}\left(\mu_{i}+\mu_{j}-1\right)-\text { Probability both signals wrong }\right)
\end{aligned}
$$$$
\text { where the conditional probability of agreement is } P\left(\zeta_{i}=z \mid \zeta_{j}=z\right)=\mu_{i} \mu_{j}+\left(1-\mu_{i}\right)\left(1-\mu_{j}\right)
$$ 
and the probability of both signals being wrong is of course $\left(1-\mu_{i}\right)\left(1-\mu_{j}\right)$. Note that this expression makes it clear that the incentive compatibility condition will hold when both players have either very precise or very imprecise signals. Further, as the investment in security quality improves, this inequality becomes harder to satisfy. This outcome reflects the complementarities between the two types of expertise; the more sensitive the security is to the outcome of the good project, the less information about this project is needed to generate adverse selection.

If neither the pooling offer equilibrium nor the pure strategy equilibrium described here exists, we assume that the responder mixes over accepting or rejecting the high offer when he has a high signal at a rate sufficient to deter a low type proposer from making the high offer. The maximum probability of acceptance that can sustain incentive compatibility is

$$
\begin{aligned}
& \frac{E\left[v_{p} \mid \zeta_{p}=0, \zeta_{r}=0\right]}{\text { Conditional probability of disagreement } \times E\left[v_{p} \mid \zeta_{p}=1, \zeta_{r}=1\right]}= \\
& \frac{-2 \mu_{i} \mu_{j}+\mu_{i}+\mu_{j}-\left(1-\mu_{i}\right)\left(1-\mu_{j}\right)(\phi+1) w_{p}-1}{\left(\mu_{i}\left(2 \mu_{j}-1\right)-\mu_{j}\right)\left(-\mu_{j}+\mu_{i}\left(\mu_{j}\left(\phi w_{p}+w_{p}+2\right)-1\right)+1\right)} .
\end{aligned}
$$

Off equilibrium path beliefs prevent the proposer with a high signal from making a slightly lower price demand. ${ }^{3}$ The appendix fully describes the equilibrium that will prevail in all regions $\left\{\omega^{i}, \omega^{j}\right\}$ of firm expertise.

Payoff functions We summarize payoffs in Figure 2, which shows an individuals payoff as a function of his own and his opponents trading expertise, and Figure 3, which shows the total surplus generated as a function of both agent's trading expertise. The important characteristics of these payoff functions are that a firm's payoff initially increases in his own trading expertise until it reaches some threshold where the type of equilibrium changes and the firm becomes too smart for its own good. Once a firm is too smart, however, further ability may raise, rather than lower, payoffs, particularly if the counterparty is also a high

\footnotetext{
${ }^{3}$ The responder's meta strategy calls for rejection at off equilibrium path offers that makes the low signal proposer indifferent between the low price demand and the higher price demand. The off equilibrium path offers thus can come from both types of proposers, and therefore the beliefs of the responder are credible.
} 


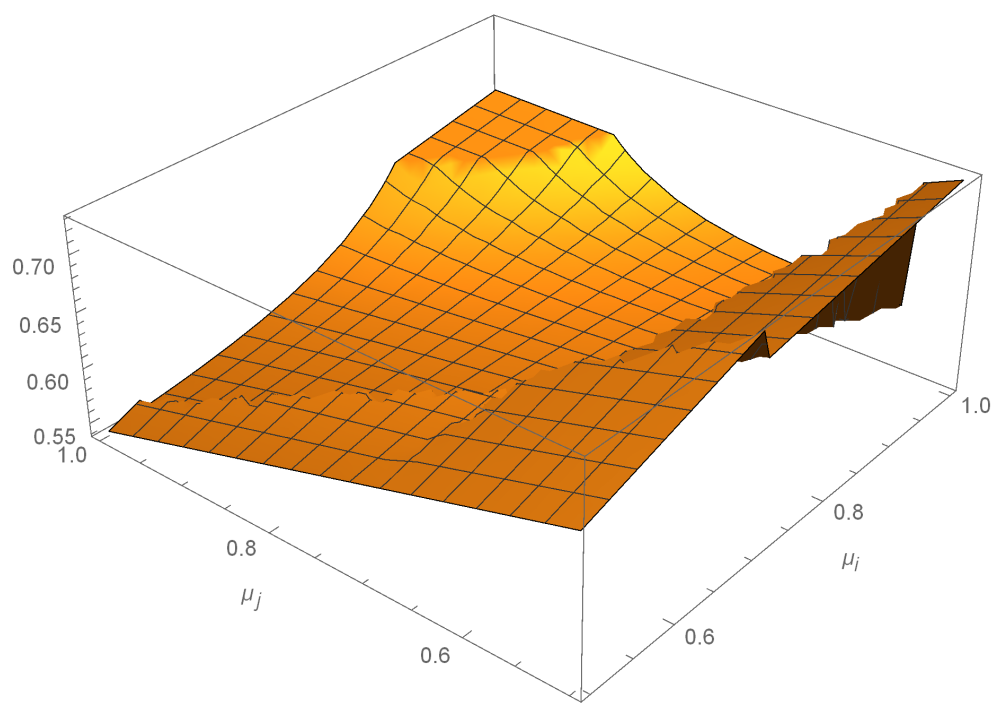

Figure 2: Payoff to agent $i$ as a function of $i$ 's trading expertise and his counterparty's trading expertise. The probability of $i$ or the counterparty producing a good security is $\frac{2}{3}$, and $\phi=2$.

trading expertise type. Further, as the level of security construction expertise increases, the region over which efficient trade can be sustained drops since information becomes more valuable as the securities improve.

Since the sign of the slope of a firm's payoff with respect to its own trading expertise will depend on the expertise levels of possible opponents, in some industry structures some firms will face strong incentives to decrease trading expertise while others face incentives to increase trading expertise.

These complexities arise specifically from the aspects of the model unique to the financial sector and differ from the canonical IO model. In contrast to the standard differentiated product game, the payoff to a firm in the stage game is not necessarily monotonically increasing in the quality ladder position. Increasing trading expertise too much can lead to greater adverse selection, particularly when one's trading partner is relatively unsophisticated. Thus, in some industry states, there is an endogenous boundary on trading expertise, as in Glode, Green, and Lowery (2012).

Further, the two-dimensional nature of firm quality may play an important role in the 


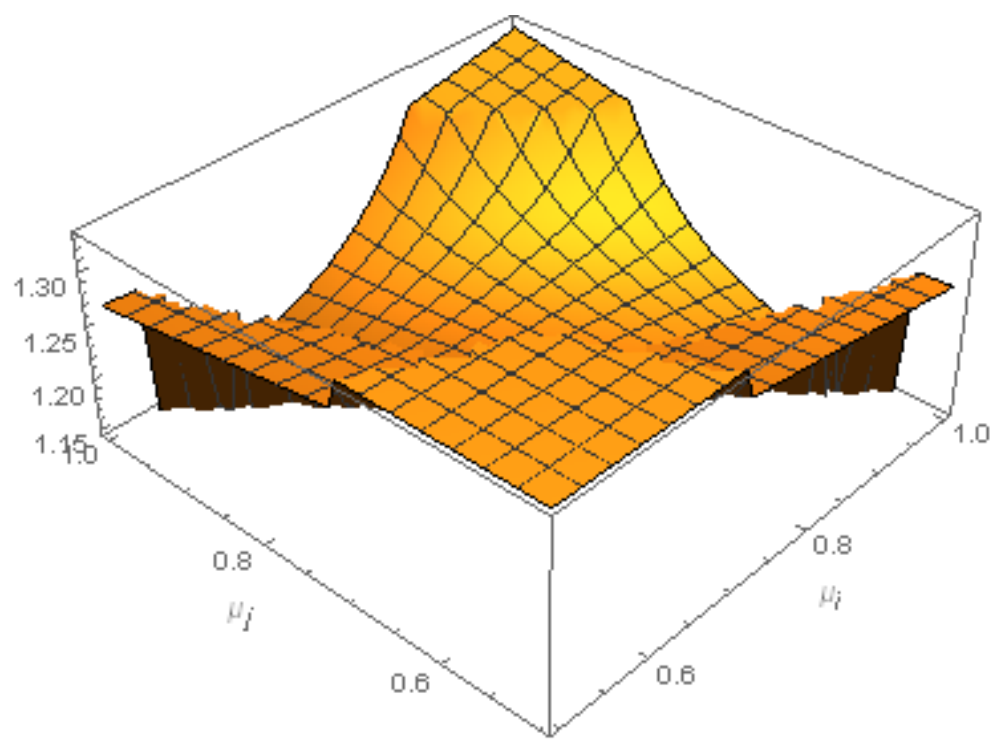

Figure 3: Total payoff to both agents as a function of each agent's trading expertise. The probability of $i$ or the counterparty producing a good security is $\frac{2}{3}$, and $\phi=2$.

dynamic incentives facing firms. In the classic IO setting, a firm that anticipates high entry and high investment has an incentive to exit or to refrain from entry. In our setting, however, the incentives for exit or entry will depend on the nature of the expected investment and the position in the state space of existing firms. If firms anticipate that others will invest heavily in surplus creation, entry becomes more appealing. If they anticipate their opponents will invest in trading expertise, however, they may prefer to exit. But, if the industry is already in a high trading expertise state, anticipating further trading expertise investment may prevent exit as firms anticipate reaching a high trading expertise equilibrium that promotes efficient trade.

\subsection{Markov-Perfect Equilibrium}

Given the payoff function $\left\{\tilde{\pi}_{i}(\boldsymbol{\omega})\right\}_{i \in \mathcal{N}_{A}(\boldsymbol{\omega})}$, a Markov-perfect equilibrium consists of value functions $\left\{V_{I}^{i}(\boldsymbol{\omega})\right\}_{i \in \mathcal{N}_{A}(\boldsymbol{\omega})}$ and policy functions $\left\{X_{I}^{i}(\boldsymbol{\omega})\right\}_{i \in \mathcal{N}_{A}(\boldsymbol{\omega})}$ for incumbents, and value functions $\left\{V_{E}^{i}(\boldsymbol{\omega})\right\}_{i \in \mathcal{N}_{I}(\boldsymbol{\omega})}$ and policy functions $\left\{X_{E}^{i}(\boldsymbol{\omega})\right\}_{i \in \mathcal{N}_{I}(\boldsymbol{\omega})}$ for entrants, such that,

(i) $X_{I}^{i}(\boldsymbol{\omega})$ solves the maximization problem in equation (2) given $\left\{X_{I}^{-i}(\boldsymbol{\omega}), X_{E}^{-i}(\boldsymbol{\omega})\right\}$, and 
$V_{I}^{i}(\boldsymbol{\omega})$ is the resulting value function,

(ii) and $X_{E}^{i}(\boldsymbol{\omega})$ solves the maximization problem in equation (3) given $\left\{X_{I}^{-i}(\boldsymbol{\omega}), X_{E}^{-i}(\boldsymbol{\omega})\right\}$, and $V_{R}^{i}(\boldsymbol{\omega})$ is the resulting value function.

\subsection{Computational Solution}

The computational solution of the dynamic model follows the algorithm described in Doraszelski and Judd (2012), extended to include two dimensions of investment. The algorithm starts with a guess for value functions $V_{I}$ and $V_{E}$ and iteratively solves the investment and entry exit problems until both policy and value functions converge. Note that for quantitatively interesting parameterizations, the computational problem is significant. For example, if the expertise quality ladder in each dimension has four levels, then each firm can be in one of 17 states $(4 \times 4$ expertise active states plus the inactive state). In an industry with ten potential firms, this implies $10^{17}$ different possible industry states $\boldsymbol{\omega}$ for which the optimization problem of incumbents and entrants has to be solved. Two features of the setup help to render the problem tractable: (i) symmetric industry states have the same solution, i.e. the individual optimizing firms do not care about the identity of their competitors, but only the distribution of other firms over expertise and activity states, and (ii) the continuous time assumption. In discrete time, all firms' investment, entry, and exit decision would occur simultaneously each period, and optimizing firms would have to form expectations over all possible industry states next period. In continuous time, only one change in the industry state can occur in a given instant. This significantly simplifies the expectation formation of optimizing firms and lowers the computational burden. 


\section{Parameter Choices and Results}

\subsection{Parameters}

Table 1 provides an overview of our parameter choices for the baseline case.

Table 1: Parameters for Benchmark Case

\begin{tabular}{l|r}
\hline \multicolumn{1}{c}{ Trading Subgame } \\
\hline $\begin{array}{l}\text { Payoff potential } \phi \\
\text { Security design expertise }\left\{\omega_{m}^{k}\right\}\end{array}$ & 2 \\
Trading expertise $\left\{\omega_{e}^{k}\right\}$ & $\{0.1, \ldots, 0.4\}$ \\
\hline \multicolumn{2}{c}{ Dynamic Game: General } \\
\hline Discount rate $\rho$ \\
Arrival of trading opportunities $\theta$ & $0.05\}$ \\
\hline \multicolumn{2}{c}{ Dynamic Game: Investment } \\
\hline Security design hazard scale $\alpha_{1, m}$ & 0.55 \\
Security design hazard exponent $\alpha_{2, m}$ & 5 \\
Tading hazard scale $\alpha_{1, e}$ & 0.8 \\
Trading hazard exponent $\alpha_{2, e}$ & 10 \\
\hline \multicolumn{2}{c}{ Exit and Entry } \\
\hline Entry cost $\Phi_{e n}$ \\
Exit scrap value $\Phi_{e x}$ \\
Entry hazard exponent $\eta_{e}$ \\
Exit hazard exponent $\eta_{x}$ \\
\hline
\end{tabular}

The trading subgame only has one parameter, $\phi$, which determines the potential payoff of a good security relative to a standard security. We set this to a value of 2 , meaning that a good security pays off twice the amount of a standard security when the hidden state realizes as $Z=1$. This payoff potential interacts with the ability of firms to actually create good securities, paramaterized by their security design expertise (the probability that they create a good project). For our benchmark calibration, we assume that the quality ladder this expertise lies in the interval between 0.1 and 0.4 , with four possible steps. Trading expertise (the signal precision) can also take one of four values, depending on a firm's level on the 
quality ladder, ranging from completely uninformative (.5) to almost perfect (.99).

For the arrival hazard for trading opportunities $\lambda\left(N_{A}\right)$, we choose the functional form

$$
\lambda\left(N_{A}\right)=\left(N_{A}\right)^{\theta}
$$

with the exponent $\theta=0.55$. This implies that the arrival of trading opportunities is increasing in the number of active firms, but at a decreasing rate. We set the discount rate $\rho$ to 0.05 .

The entry cost and the scrap value for exiting firms are set to constant values that we make dependent on the average flow profits of a firm in the industry. Specifically, we set the entry cost to $\Phi_{e n}=0.2 \times \frac{\operatorname{Mean}(\tilde{\pi}(\boldsymbol{\omega}))}{\rho}$, and the scrap value is set to $\Phi_{e x}=0.75 \times \Phi_{e n}$. This makes it generally attractive for firms to enter, and also leads to non-trivial exit if a firm or its trading partners experience adverse shocks to expertise.

We specify the entry and exit hazards as polynomial functions of the respective investment choices, i.e. we set

$$
h_{e n}^{z}\left(x^{i, z}\right)=\left(x^{i, z}\right)^{\eta_{e}}, \quad h_{e x}^{z}=\left(x^{i, z}\right)^{\eta_{x}} .
$$

For the investment hazards, we allow for both a linear coefficient and an exponent:

$$
h^{k}\left(x^{i, k}\right)=\alpha_{k, 1}\left(x^{i, k}\right)^{\alpha_{k, 2}}
$$

for $k=m, e$, respectively. The parameters on the effectiveness of investment were selected such that both sectors showed non-trivial investment dynamics, and the entry/exit parameters were selected to generate industries that varied in size within the 1 to 8 industry bound.

After obtaining the policy functions by numerically solving the model, we simulate the industry for 1000 total events. As is standard, we discard a number of periods at the beginning of the simulation to avoid initial conditions effects. 

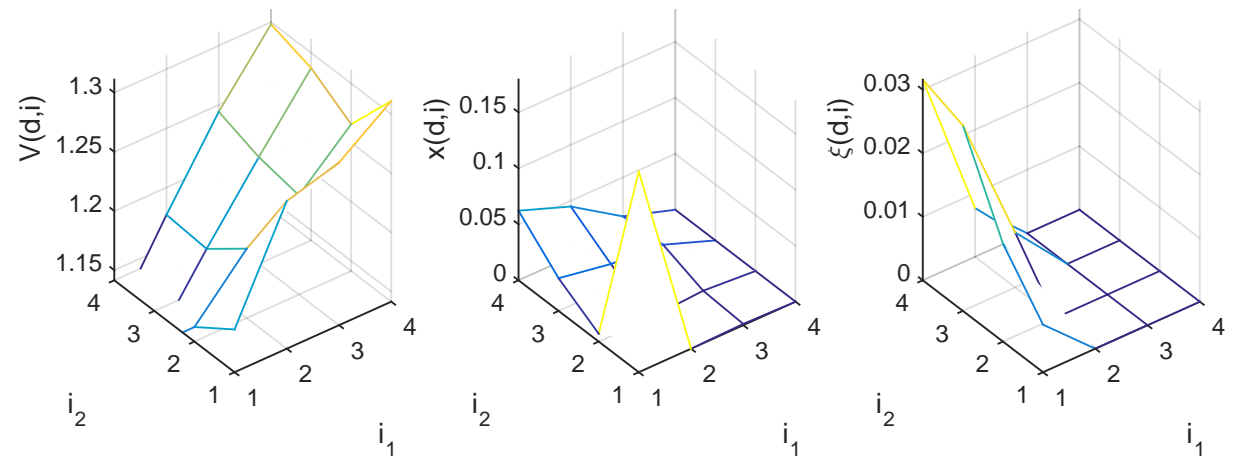

Figure 4: Value function, trading expertise and exit policy functions for two active firms. The axis labeled $i_{1}$ represents the trading expertise level of the firm in question, while $i_{2}$ represents the trading expertise of the opponent. The left-hand graph is the value function, the middle graph investment and the right-hand graph is the exit policy.

\subsection{Policy Functions}

Before analyzing the simulation results, it is helpful too look at the policy and value functions of the firms in the benchmark industry. Figure 4 displays the investment policy (middle) and exit policy (right) of an incumbent firm when there are only two active firms in the industry. When one's opponent has high trading expertise in this duopoloy setting, any drop of one's own expertise is immediately met with high investment in trading expertise, represented by the elevated region of the policy function at the back left of the figure. Another interesting phenomenon is apparent in this policy function. When one's opponent's expertise is low, firms have a strong incentive to invest to get to a medium level (quality ladder position 3) of trading expertise. This incentive relates to the non-monotonic shape of the stage game payoff function. Moving up to level 3 against a weak opponent is valuable, but moving further up raises the risk of generating adverse selection. The same forces affect the optimal exit decision: a firm with little own trading expertise that faces a highly informed opponent is more likely to exit the industry. Inspecting the associated value function in the left-hand graph confirms this intuition. 


\subsection{Benchmark Calibration}

Table 2 shows several statistics of the simulated industry for the baseline calibration. The first column shows statistics for all simulation periods, while the columns to its right contain simulation moments conditional on a certain industry size. During the simulation, many different industry configurations occur, with the modal industry having four (out of the eight possible) firms. The average flow profit, computed as the sum of all expected flow profits of individual active firms, is 1.84. The flow profit includes revenues from asset sales net of investment expenses. It is not adjusted for discrete profit events, which are entry costs and

exit sale revenues. As security production and trading opportunities arrive more frequently in larger industries, flow profit increase with industry size. Average production expertise is 0.19 , indicating a moderate degree of investment in this type of firm quality (recall that the possible range is $[0.1,0.4])$. There is considerable cross-sectional heterogeneity in design expertise with the time-series mean of the difference between the most and least skilled firms being 0.24 . Average trading expertise is only 0.53 and hence hardly above the lower bound of 0.5 . The industry is concentrated with the largest two firms on average getting $51 \%$ of all profits, but this is mainly due to the industry size being 4 firms or less for $57 \%$ of the time. Prices in the industry are stable around the mean of 0.53 . Since there is little heterogeneity in trading expertise, the majority of transaction in this industry take place at the pooling price.

\subsection{Increasing security complexity}

Our main experiment is to vary the interval for possible levels of security design expertise. We will consider two experiments: (i) moving the baseline interval of $[0.1,0.4]$ to a higher level $[0.4,0.7]$ (but keeping fixed the size), and (ii) widening the interval to $[0.1,0.7]$. We keep all other parameters fixed at the baseline. 


\begin{tabular}{l|c|c|cccccccc}
\hline & All & \multicolumn{10}{c}{ Conditional on N active firms } \\
& & 0 & 1 & 2 & 3 & 4 & 5 & 6 & 7 & 8 \\
\hline M(Act. firms) & 4.31 & & & & & & & & & \\
SD(Act. firms) & 1.38 & & & & & & & & & \\
Fraction time & 1.00 & 0.00 & 0.01 & 0.05 & 0.19 & 0.32 & 0.29 & 0.12 & 0.03 & 0.00 \\
\hline M(Flow profit) & 1.84 & 0.00 & -0.06 & 0.74 & 1.24 & 1.72 & 2.17 & 2.58 & 2.95 & 3.41 \\
SD(Flow profit) & 0.30 & 0.00 & 0.00 & 0.00 & 0.01 & 0.01 & 0.01 & 0.02 & 0.02 & 0.00 \\
M(Design exp.) & 0.19 & 0.00 & 0.24 & 0.21 & 0.19 & 0.19 & 0.19 & 0.18 & 0.18 & 0.18 \\
M(Trading exp.) & 0.53 & 0.00 & 0.56 & 0.56 & 0.54 & 0.53 & 0.53 & 0.52 & 0.51 & 0.51 \\
M(Max-Min(Design exp.)) & 0.24 & 0.00 & 0.14 & 0.18 & 0.22 & 0.23 & 0.26 & 0.27 & 0.28 & 0.30 \\
M(Max-Min(Trading exp.)) & 0.11 & 0.00 & 0.06 & 0.12 & 0.10 & 0.10 & 0.12 & 0.11 & 0.09 & 0.07 \\
\hline Concent. 1 & 0.26 & 0.00 & 1.00 & 0.51 & 0.34 & 0.26 & 0.21 & 0.17 & 0.15 & 0.13 \\
Concent. 2 & 0.51 & 0.00 & 1.00 & 1.00 & 0.67 & 0.51 & 0.41 & 0.34 & 0.29 & 0.26 \\
Concent. 3 & 0.73 & 0.00 & 1.00 & 1.00 & 1.00 & 0.76 & 0.61 & 0.51 & 0.44 & 0.38 \\
\hline M(Entry haz.) & 0.72 & 0.00 & 1.41 & 1.32 & 1.02 & 0.83 & 0.52 & 0.26 & 0.11 & 0.00 \\
M(Exit haz.) & 0.72 & 0.00 & 0.18 & 0.16 & 0.35 & 0.60 & 0.92 & 1.29 & 1.18 & 1.22 \\
M(Aver. price) & 0.53 & 0.00 & 0.00 & 0.51 & 0.54 & 0.54 & 0.54 & 0.54 & 0.54 & 0.54 \\
M(Price dispersion) & 0.03 & 0.00 & 0.00 & 0.03 & 0.03 & 0.03 & 0.03 & 0.03 & 0.03 & 0.03 \\
\hline
\end{tabular}

Table 2: Summary statistics for three levels of trading expertise investment effectiveness.

Unconditional Moments The first experiment implies that all securities created in the industry with security design interval $[0.4,0.7]$ are at least as good as, and in fact on average much better quality than, the securities produced in the baseline economy. Any entering firm now produces a high-quality security with probability 0.4 , a level that can only be reached with substantial investment in the baseline economy (where average security production expertise is 0.19). Increasing the average quality of the securities also increases the incentives for investing in trading expertise, since for a given trade there is now greater uncertainty about the type of security.

Figure 5 displaying the distribution of active firms and flow profit from both industries, with the wide bars showing the baseline and the narrow bars the high-expertise economy. It is immediately obvious that the high-expertise industry has an average lower participation. Partially through this channel, despite producing higher quality securities on average by construction the higher surplus creation industry generates fails to generate higher profits. In fact, both the participation and the profit distributions are shifted left. The new industry 

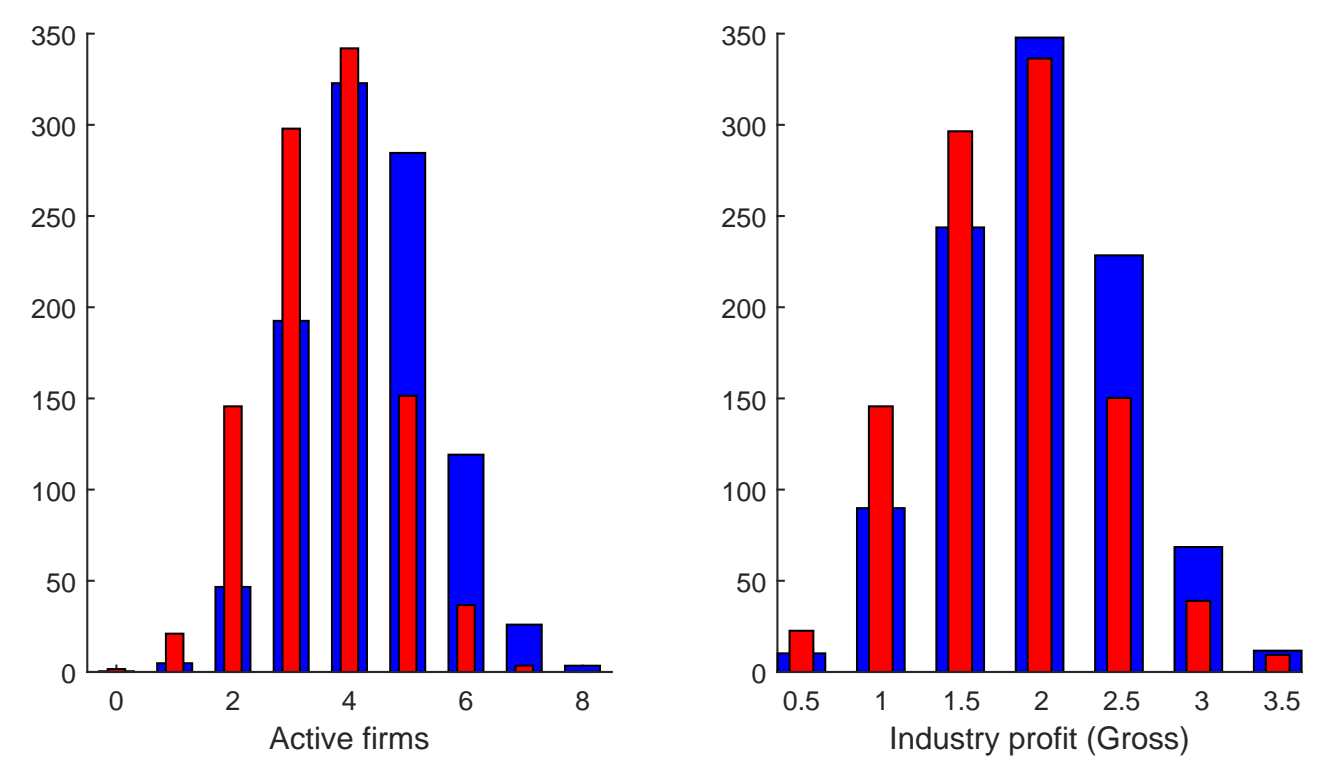

Figure 5: Distribution of active firms and industry flow profit for baseline (wide blue bars) and high-expertise (narrow red bars) industries.

features significantly more frequent episodes with two or fewer active firms and close to zero profits.

Table 3 provides additional moments from the simulated distributions of both industries. The numbers in the first two columns of the table confirm that both the average number of firms and flow profit decrease. The flow profit also becomes more volatile, reflecting the thicker left tail of the distribution. The reason becomes apparent by inspecting the average skill levels of firms in the industries. While design expertise rises by construction, the high-expertise industry also features an endogenous increase in trading expertise, with the mean rising from 0.53 to 0.61 and the average of the maximum difference between to active firms increasing to 0.21 . It is this inequality in trading expertise that causes the lower participation in the high-expertise industry. As all securities exhibit a greater scope for the usefulness of information, firms invest more in trading expertise. As some firms succeed, potential entrants and incumbent with lower levels of trading expertise are now facing a worse position when trading with the highly informed firms. This adverse selection effect leads to 


\begin{tabular}{l|rr|rr}
\hline & \multicolumn{2}{|c|}{$\alpha_{2, e}=10$} & \multicolumn{2}{|c}{$\alpha_{2, e}=0$} \\
\hline Design Expertise Interval & {$[0.1,0.4]$} & {$[0.4,0.7]$} & {$[0.1,0.4]$} & {$[0.4,0.7]$} \\
\hline M(Act. firms) & 4.31 & 3.58 & 4.90 & 4.69 \\
SD(Act. firms) & 1.38 & 1.25 & 1.46 & 1.54 \\
M(Flow profit) & 1.84 & 1.78 & 2.15 & 2.39 \\
SD(Flow profit) & 0.30 & 0.37 & 0.33 & 0.47 \\
Net profit rate & 2.06 & 1.98 & 2.35 & 2.59 \\
\hline M(Design exp.) & 0.19 & 0.48 & 0.21 & 0.50 \\
M(Trading exp.) & 0.53 & 0.61 & 0.50 & 0.50 \\
M(Max-Min(Design exp.)) & 0.24 & 0.19 & 0.27 & 0.26 \\
M(Max-Min(Trading exp.)) & 0.11 & 0.21 & 0.00 & 0.00 \\
\hline Concent. 1 & 0.26 & 0.33 & 0.23 & 0.24 \\
Concent. 2 & 0.51 & 0.62 & 0.45 & 0.47 \\
Concent. 3 & 0.73 & 0.84 & 0.66 & 0.68 \\
\hline M(Aver. price) & 0.53 & 0.56 & 0.55 & 0.63 \\
M(Price dispersion) & 0.03 & 0.11 & 0.03 & 0.03 \\
\hline
\end{tabular}

Table 3: Comparison of baseline to high expertise industries. Left two columns for baseline level of investment effectiveness; right two columns for ineffective investment in trading expertise. 
smaller industries. The decrease in participation is so large in this case that it completely offsets the mechanical increase in profits from better securities. The table shows further that the high expertise industry also is more concentrated and features greater dispersion in prices.

As an additional experiment, we shut down investment in trading expertise completely by setting the scale parameter of the corresponding investment success hazard $\left(\alpha_{2, e}\right)$ to zero. The right two columns of table 3 show statistics for the ergodic distribution of industries with the $[0.1,0.4]$ and $[0.4,0.7]$ design expertise intervals, respectively. The number of active firms and the flow profit are higher for both intervals, when compared to the industries with higher investment effectiveness in the left two columns. Furthermore, flow profit now also increases substantially when the design expertise interval shifts up. This shows that by preventing firms from investing in trading expertise, it is possible to suppress the negative effect on the extensive margin. This result confirms that the drop in participation we see for the baseline value of $\alpha_{2, e}=10$, and the resulting lower industry profit despite higher quality securities, is driven by the incentives to invest in trading expertise.

Time series properties In figure 6 we compare the simulated time series of the number of active firms and surplus for the baseline and the [0.4,0.7] industries. Both time series are lower on average as could already be seen in table 3. The time series further show that the high-expertise economy has more frequent "breakdowns", which are periods when the number of active firms drops to one or zero and industry profit plummets.

The reason for these breakdown episodes is high investment in trading expertise. This investment leads to industry states in which one firm moves to a higher trading expertise level than other active firms. This in turn causes lower trading profits and higher exit rates for the other firms. The strong negative correlation between the number of active firms and the difference between in trading expertise between the most and least expert firms is apparent in figure 7 . 


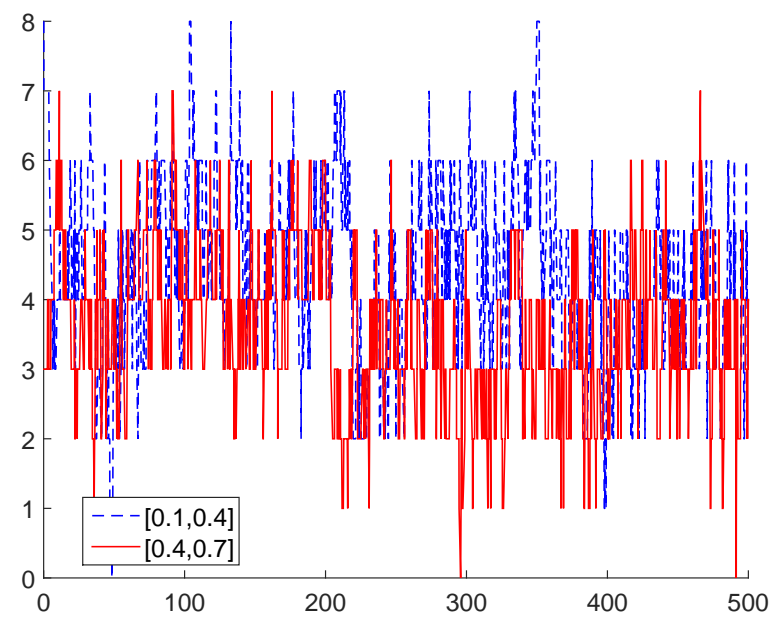

(a) Number of active firms.

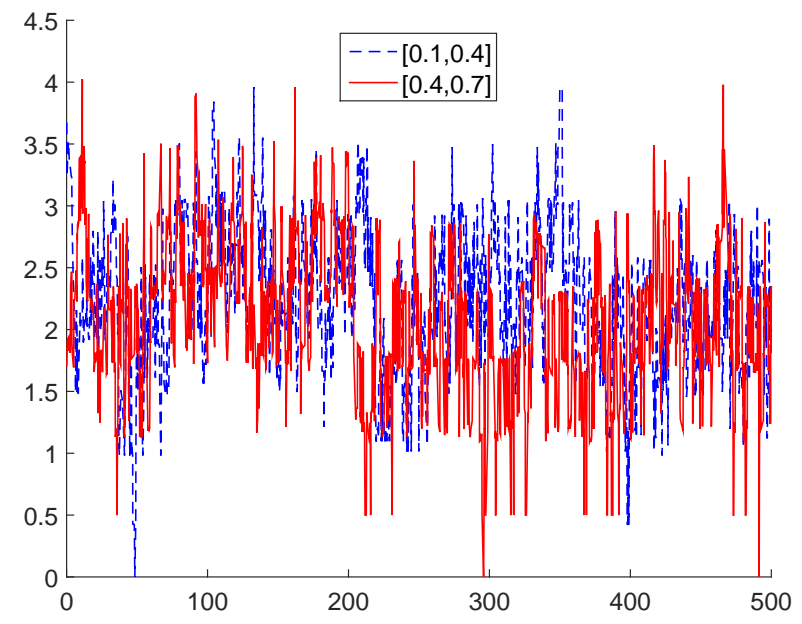

(b) Flow profit.

Figure 6: Number of active firms and flow profit for first 500 units of time in simulation. Comparing baseline (dashed blue) to high-expertise (solid red).

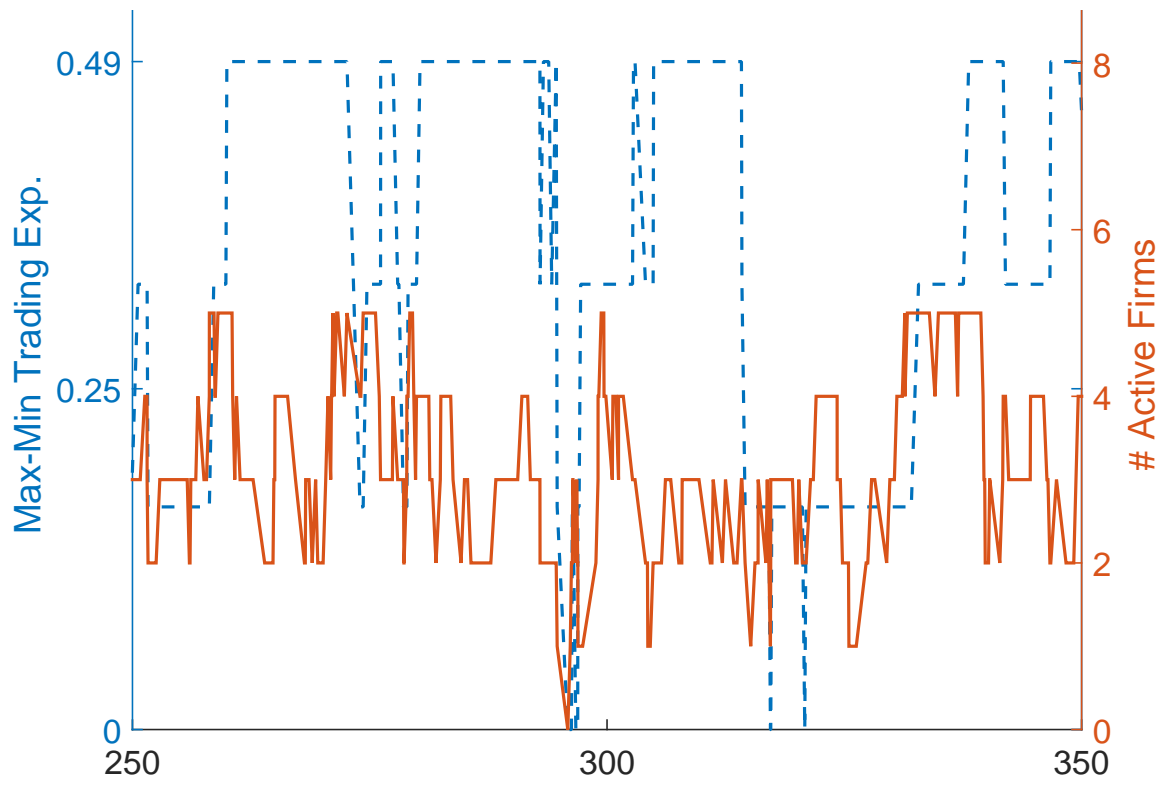

Figure 7: Number of active firms and the difference between trading expertise of the firm with the highest expertise and the firm with lowest expertise for the high expertise economy. 

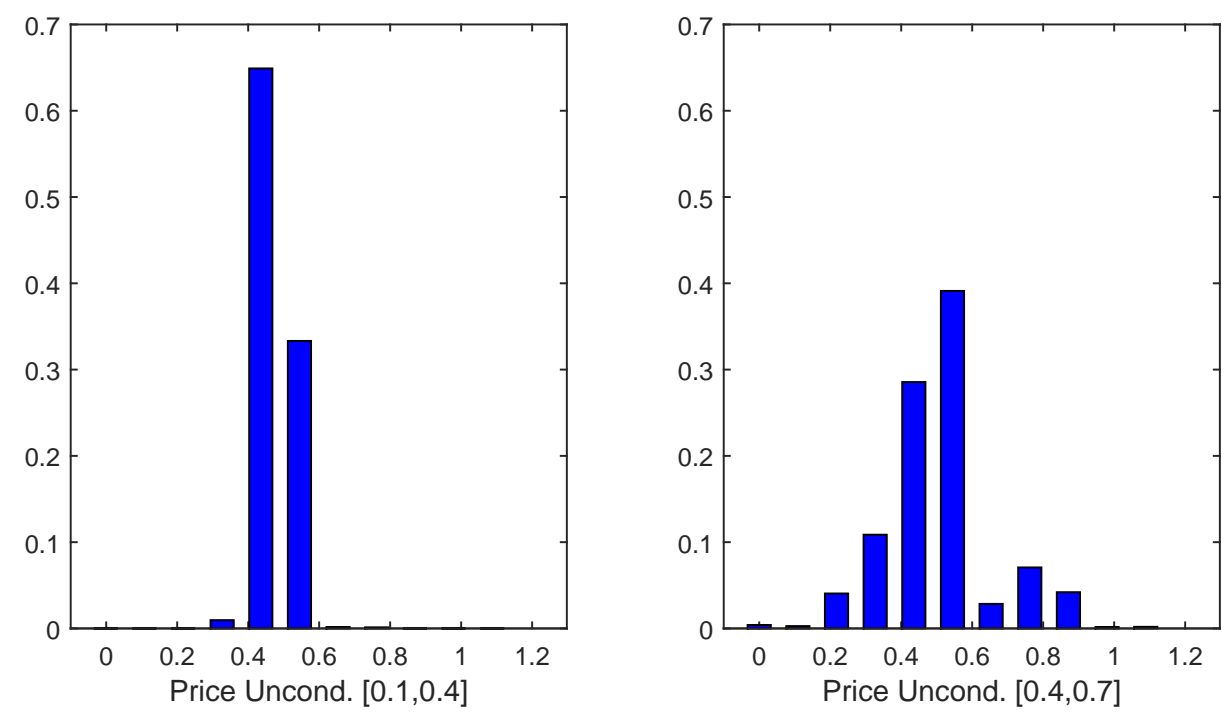

Figure 8: Price distribution in baseline (left) and high-expertise (right) industries.

Price Distribution Prices at which securities trade are more dispersed in the highexpertise industry, as shown in figure 8.

In the left panel, prices in the baseline economy are very concentrated around the mean. This reflects that almost all trades in the baseline economy occur at the pooling price, and differences in prices are driven almost entirely by differences in security design expertise, which are relatively minor.

In the high-expertise economy (right panel), however, prices have both a left and a right tail. These are the high and low prices from the separating equilibrium of the trading game. Recall that this equilibrium occurs when the signal precision, i.e. the levels of trading expertise, of the two trading firms are sufficiently different. Since the high expertise industry exhibits greater heterogeneity in expertise, it therefore also exhibits greater price dispersion. The positive mass at zero reflects trade breakdowns due to adverse selection in the separating equilibrium. 


\section{Conclusion}

We analyze a model of industry dynamics in the financial sector. This sector is categorized by potential complementarities in entry payoffs and multiple dimensions of firm quality. One dimension of quality, the production of securities, generates positive externalities for other market participants. The other dimension, trading expertise, simply provides a zero-sum advantage to the firm. Our model is able to generate several of the prominent stylized facts that have been documented for financial securities traded in decentralized markets. In particular, we find that markets for securities that have a greater potential for information acquisition by traders, also tend to be more concentrated and fragile, and exhibit greater price dispersion and heterogeneity in the expertise of the participating firms. We believe that the modeling framework is suited for a quantitative analysis of industry dynamics in finance, moving beyond matching stylized facts. Our focus in this paper is on securities traded in decentralized markets. In future work, we are also planning to apply our methodology to securities markets with central trading. 


\section{A Full equilibrium description}

In this section, variables are indexed such that subscript $p$ identifies the proposer (who will always be the liquidity demander) and subscript $r$ identifies the responder. To simplify some of the expressions, it is also useful to define $q=\frac{Q_{p}}{1-Q_{p}}$.

Proposition. Suppose $\mu_{p} \leq \frac{1+\mu_{r}(q-(\phi+1))+q}{\mu_{j}(1+\phi+2 q)-q}$. In the case where the proposer is the liquidity demander, the unique, efficient perfect sequential equilibrium where the proposer offers a price of $\left(1-\mu_{r}\right)\left[Q_{p} \frac{1}{2}(\phi+1)+\left(1-Q_{p}\right) \frac{1}{2}\right] \leq q$ and the responder always accepts.

See main text for proof derivation of the threshold. Uniqueness follows from arguments identical to those in Glode, Green, and Lowery (2012) which establishes the threshold for perfect sequential equilibria.

Proposition. In the case where the proposer is the liquidity demander and the above condition for pooling does not hold, there exists a perfect sequential equilibrium where

1. The proposer offers

(a) $\Pi_{S}^{l o}$ if his signal is high

(b) $\Pi_{S}^{\text {hi }}$ if his signal is low.

2. The responder always accepts the low demand and accepts the high demand if and only if his signal is high.

if and only if $\Pi_{S}^{l o} \geq P\left(\zeta_{r}=1 \mid \zeta_{p}=0\right) \Pi_{S}^{h i}$. This equilibrium maximizes the probability of trade for all equilibria in which the proposer and responder use a pure strategy.

Proof. As argued in the main text, this incentive compatibility condition implies that the proposer with the low signal will prefer the low offer to demanding the high price and risking rejection when the signal of the responder agrees with the low signal of the proposer. The equilibrium that could generate more trade is where the high signal proposer asks for $E\left[v_{p} \mid \zeta_{p}=1, \zeta_{r}=0\right]$. If the responder plays a pure strategy, the responder with the low signal 
either accepts the offer always or rejects the offer always. In the first case, this is clearly not an equilibrium since the low type proposer will now ask for the higher price. In the second case, the responder with the low signal rejects the offer. But, if the high ask is always rejected, the high type deviates to asking for the low price. But, by the same arguments that establish the bound for a perfect sequential equilibrium, having both players offer the price given two low signals is also not an equilibrium.

Proposition. In the case where the proposer is the liquidity demander, if neither of the above conditions hold the perfect sequential equilibrium with the most trade occurs when the proposer makes the same offers as in proposition A, the responder accepts the low price demand, and the responder accepts the high price demand with probability given in equation 7.

Proof. The proposition is a direct consequence of computing the probability of acceptance necessary to maintain incentive compatibility such that the low type. Direct computation shows that, in all regions where the first two propositions do not apply, the implied acceptance probability is between 0 and 1 . Thus, the equilibrium exists. 


\section{References}

Afonso, G. (2011): "Liquidity and congestion," Journal of Financial Intermediation, 20(3), 324-360.

Atkeson, A. G., A. L. Eisfeldt, and P.-O. Weill (2013): "The market for otc derivatives," Discussion paper, National Bureau of Economic Research.

2292.

(2015): "Entry and exit in otc derivatives markets," Econometrica, 83(6), 2231-

Babus, A., And T.-W. Hu (2015): "Endogenous Intermediation in Over-the-Counter Markets," CEPR Discussion Papers 10708, C.E.P.R. Discussion Papers.

Babus, A., And P. Kondor (2013): "Trading and information diffusion in OTC markets," CEPR Discussion Papers 9271, C.E.P.R. Discussion Papers.

Bolton, P., T. Santos, and J. A. Scheinkman (2015): "Cream skimming in financial markets," Discussion paper, National Bureau of Economic Research.

Chaderina, M., and R. C. Green (2014): "Predators and Prey on Wall Street," Review of Asset Pricing Studies, p. rau003.

Chang, B. (2014): "Adverse Selection and Liquidity Distortion in Decentralized Markets," Working Paper 157, Wisconsin School of Business.

Daley, B., And B. Green (2012): "Waiting for News in the Market for Lemons," Econometrica, 80(4), 1433-1504.

Diamond, D. W., And P. H. Dybvig (1983): "Bank runs, deposit insurance, and liquidity," The journal of political economy, pp. 401-419.

Doraszelski, U., AND K. L. JudD (2012): "Avoiding the curse of dimensionality in dynamic stochastic games," Quantitative Economics, 3(1), 53-93.

Doraszelski, U., And M. SAtTerthwaite (2010): "Computable Markov-perfect industry dynamics," The RAND Journal of Economics, 41(2), 215-243.

Duffie, D., N. Grleanu, and L. H. Pedersen (2005): "Over-the-Counter Markets," Econometrica, 73(6), 1815-1847.

EisenberG, L., And T. H. Noe (2001): "Systemic Risk in Financial Systems," Management Science, 47(2), 236-249.

Ericson, R., And A. PAkes (1995): "Markov-Perfect Industry Dynamics: A Framework for Empirical Work," Review of Economic Studies, 62(1), 53-82. 
Farboodi, M. (2015): "Intermediation and Voluntary Exposure to Counterparty Risk," Working Paper 365, Princeton University.

Glode, V., R. C. Green, and R. Lowery (2012): "Financial expertise as an arms race," The Journal of Finance, 67(5), 1723-1759.

Glode, V., And R. Lowery (2015): "Compensating Financial Experts," The Journal of Finance, Forthcoming.

Golosov, M., G. Lorenzoni, and A. Tsyvinski (2014): "Decentralized Trading With Private Information," Econometrica, 82(3), 1055-1091.

Green, R. C., B. Hollifield, and N. Schürhoff (2007): "Financial intermediation and the costs of trading in an opaque market," Review of Financial Studies, 20(2), 275314 .

Guerrieri, V., And R. Shimer (2012): "Dynamic Adverse Selection: A Theory of Illiquidity, Fire Sales, and Flight to Quality," NBER Working Papers 17876, National Bureau of Economic Research, Inc.

Ljungqvist, A., F. Marston, and W. J. Wilhelm (2009): "Scaling the hierarchy: How and why investment banks compete for syndicate co-management appointments," Review of Financial Studies, 22(10), 3977-4007.

Pakes, A., And P. MCGuire (1994): "Computing Markov-Perfect Nash Equilibria: Numerical Implications of a Dynamic Differentiated Product Model," The Rand Journal of Economics, pp. 555-589. 